\title{
Oral Manifestations, Gingival Index and Dental State of Vesiculobullous Diseases
}

\author{
Sergio Eduardo Migliorini ${ }^{*}$, Vanessa Gallego Arias Pecorari ${ }^{2}$, Marcio Zaffalon Casati ${ }^{3}$, \\ Claudia Giuli Santi ${ }^{4}$, Cyro Festa Neto ${ }^{4}$, Luciano Lauria Dib ${ }^{5}$ \\ ${ }^{1}$ Paulista University (UNIP), Sao Paulo, Brazil \\ ${ }^{2}$ Department of Bioestatistic, Paulist University (UNIP), Sao Paulo, Brazil \\ ${ }^{3}$ Department of Peridontal, Campinas State University, Sao Paulo, Brazil \\ ${ }^{4}$ Department of Dermatology, University of São Paulo, Sao Paulo, Brazil \\ ${ }^{5}$ Department of Stomatology, Paulist University (UNIP), Sao Paulo, Brazil \\ Email: ^smigliorini@terra.com.br, pecorari.vanessa@yahoo.com.br, casati@fob.unicamp.br, cgiulisanti@uol.com.br, \\ cfesta@uol.com.br, lldib@uol.com.br
}

How to cite this paper: Migliorini, S.E., Pecorari, V.G.A., Casati, M.Z., Santi, C.G., Neto, C.F. and Dib, L.L. (2018) Oral Manifestations, Gingival Index and Dental State of Vesiculobullous Diseases. International Journal of Clinical Medicine, 9, 408-422.

https://doi.org/10.4236/ijcm.2018.95035

Received: February 20, 2018

Accepted: May 15, 2018

Published: May 18, 2018

Copyright $\odot 2018$ by authors and Scientific Research Publishing Inc. This work is licensed under the Creative Commons Attribution International License (CC BY 4.0).

http://creativecommons.org/licenses/by/4.0/

\begin{abstract}
Objective: To determine the occurrence of oral manifestations, gingival index, dental state and associated therapeutic aspects in patients with vesiculobullous diseases. Study design: Prospective and observational study conducted with 69 patients from May 2013 to May 2014 at the Dermatology Outpatient Clinic of the Clinical Hospital, University of São Paulo Medical School, Brazil. Data were analyzed for frequency in absolute values, percentage and correlation using the Chi-square test. Results: $84.1 \%$ of the patients had oral manifestations of vesiculobullous diseases ( $\mathrm{p}=0.001) ; 25 \%$ had gingival lesions; $18.2 \%$ had lesions in the buccal mucosa, and $17.6 \%$ in the lips, with no correlation between the location and the type of disease $(p=0.990)$. Among all patients with bullous pemphigoid, linear IgA dermatosis, and mucous membrane pemphigoid, 59 (93.6\%) patients had gingival inflammation of dental origin but without significant correlation $(\mathrm{p}=0.42)$. There was correlation between pemphigus vulgaris and periodontal disease $(p=0.05)$. Conclusion: Gingival inflammation seems to interfere negatively with the clinical course of these diseases. Further studies should be conducted to better clarify the interrelations between dental and gingival state, and between vesiculobullous diseases and oral involvement.
\end{abstract}

\section{Keywords}

Oral Medicine, Autoimmune Diseases, Pemphigus, Periodontal Diseases, Bullous Pemphigoid 


\section{Introduction}

Vesiculobullous diseases (VBDs) represent a heterogeneous group of rare autoimmune diseases characterized by formation of blisters in the skin and mucous membranes [1]. They can be divided into two main categories according to the cleavage plane: intra epidermal, as in pemphigus; and basement membrane zone, as in the group of sub epidermal bullous diseases [1].

These disorders, in particular the pemphigus group, are crucial for the morbidity associated with skin and mucous membrane involvement, especially in untreated cases [2]. The rupture of blisters leads to painful erosions that cause significant loss of fluids, electrolytes and proteins, especially in cases of extensive body surface area affected. These lesions may be associated with secondary systemic complications that can be fatal [1].

When these lesions affect the oral mucosa, pharynx and esophagus, patients may lose food and medicine intake ability, with significant loss of quality of life and weight and body mass [1] [3]. In many cases, it is difficult to know whether oral lesions of VBDs are the cause of inflammatory gingival disease, or if this disease maintains or aggravates such oral lesions [4] [5].

The most common oral manifestation is desquamative gingivitis, sometimes mistaken for gingival inflammatory lesion originating from bacterial plaque or dental biofilm [6], which can delay the diagnosis and appropriate treatment. On the other hand, the persistence of oral lesions implies prolonging drug therapies [7].

In this way, the course of the disease is uncertain, alternating with periods of chronicity and acute exacerbation, varying according to the drug therapy and the individual characteristics of the patients [8]. Treatments are challenging, because they require high doses of systemic corticosteroids and immunosuppressant associated with several adverse side effects and high risk of severe systemic complications [1].

Since there were no studies assessing the occurrence of oral lesions with associated inflammatory gingival index, the goal of present study was to contribute to the literature by determining the occurrence of oral manifestations, gingival index, dental state and therapeutic aspects of patients with VBDs.

\section{Materials and Methods}

\subsection{Study Type}

This is a prospective, observational study conducted with 69 patients treated at the Dermatology Outpatient Clinic of the Clinical Hospital, University of Sao Paulo Medical School (HC-FMUSP), Brazil, from May 2013 to May 2014. The study was approved by the Ethics Research Committee of the HC-FMUSP-CAPPesq, under Opinion $n^{\circ} 469,955$.

The criteria for inclusion were: patients diagnosed with VBDs-pemphigus vulgaris; paraneoplastic pemphigus; mucous membrane pemphigoid; gestational pemphigoid; epidermolysis bullosa; IgA pemphigus; linear IgA dermatosis; and 
bullous pemphigoid-confirmed by histopathological and direct immunofluorescence examination; presence or history of with oral involvement; without age restrictions; and treated at the abovementioned outpatient clinic during the period proposed for the study.

The criteria for exclusion were: patients with dermatologic diseases without confirmed histopathological diagnosis; patients with acute manifestation associated with reactions caused by drugs or food; and patients with no oral cavity involvement or genetic bullous disease.

\subsection{Data Collection}

Data collection was performed every Monday afternoon. Patients treated by the dermatologist were previously contacted by researcher, who explained the purpose of study. After accepting to participate in the study, patients signed an informed consent form and the authorization to use images of lesions.

A dental surgeon assessed oral cavity of patients included in study during routine treatment of bullous lesions at outpatient clinic. For these assessments, patients were placed in seated position with artificial lighting and subjected to intraoral examination for only one researcher starting by inspection of lips, tongue, gingiva, floor of mouth, buccal mucosa, soft palate and hard palate. Mucosal changes with suspicion of VBDs were tested for Nikolsky's sign by applying pressure with wooden spatulas.

Changes in gingival inflammation were assessed in accordance with a modified gingival index [9] to determine gingival inflammation by color, gingival contour changes or spontaneous bleeding. The gingiva examined should be away from region affected by desquamative gingivitis. Patients were examined visually without periodontal probes. Four gingival units per tooth (two marginal and two papillary) were assessed and classified according to four levels of the modified gingival index, namely: 0 = absence of inflammation; $1=$ mild inflammation or slight variations in color and texture, but not in all parts of the free or papillary gingiva; 2 = slight inflammation in all portions of the free or papillary gingiva; 3 = moderate, bright inflammation of the surface, erythema, edema and/or free or papillary gingiva hypertrophy; 4 = severe inflammation: erythema, edema and/or free gingival hypertrophy with spontaneous papillary bleeding, congestion or ulceration. Thus, patients were distributed into two groups: (A) patients without gingival changes; and (B) patients with changes at levels 1, 2, 3, and 4.

Regarding the presence of teeth, patients were distributed into three categories: 1) totally dentulous patients: no tooth loss; 2) partially dentulous patients: loss of at least one tooth; 3) totally edentulous patients: total tooth loss. When patients wore dental prostheses (partial or complete), they were categorized as: patients with fixed prostheses, with no possibility of spontaneous removal; and patients with removable prostheses, with possibility of spontaneous removal.

Injuries were photographed using a Canon G7X camera obtaining three lateral and frontal photographs. Data from medical records were used to complement 
the assessment of patients (demographic data, diagnosis, treatment history and clinical evolution).

\subsection{Data Analysis}

Data collected were entered into an Excel spreadsheet for Mac 2011. Analysis of descriptive data consisted in presenting the frequencies in absolute values, percentage, averages and standard deviations. The correlation between frequencies was obtained using the Chi-square test in SPSS 20.0 (IBM, Chicago, IL).

\section{Results}

A total of 105 patients were treated during study period. Only 69 patients met inclusion criteria and were included in study. The 36 excluded patients did not have autoimmune disease. The average age of the patients was $50.8 \pm 17$ years. There was a predominance of female and white patients $(68.1 \%$ and $85.5 \%$, respectively); 38 (55.1\%) patients had started outpatient treatment, and 31 (44.9\%) had started the treatment in another institution and were referred to the HC-FMUSP due to failure of the initial therapy.

Of the 69 patients assessed, $58(84.1 \%)$ had oral manifestations of VBDs at time of examination. These oral manifestations were present in patients with paraneoplastic pemphigus, pemphigus vulgaris, mucous membrane pemphigoid, bullous pemphigoid and acquired epidermolysis bullosa. The other 11 (15.9\%) did not present oral lesions at time of physical examination, but had history of oral manifestations.

Two patients had paraneoplastic pemphigus. They presented oral lesions on the lip, tongue, floor of mouth, buccal mucosa, gingiva and, in the case of one patient, also on the soft palate. Both patients had gingival/periodontal disease.

Patients with pemphigus vulgaris in this study had higher incidence of gingival lesions (four cases); followed by jugular mucosa with gingiva (three cases), floor of mouth with buccal mucosa and gingiva (three cases); lip, tongue and buccal mucosa (two cases); lip, tongue, buccal and gingival mucosa (two cases); lip and gingiva (two cases); lip, buccal and gingival mucosa (two cases); and lip, tongue, buccal mucosa, gingiva, soft palate and hard palate (two cases). Of these, 28 patients had gingival/periodontal disease.

Only one patient was identified as having mucous membrane pemphigoid with oral manifestation and identified gingival/periodontal lesion. In this case, lesions are present on the lip, buccal mucosa, gingiva and soft palate.

Although uncommon, three of the four patients diagnosed with bullous pemphigoid presented oral manifestations in the tongue $(n=2)$, and in one case, also in the floor, buccal mucosa and gingiva.

Of the six patients with acquired bullous epidermolysis (ABE) found in this study, one had lip lesions only, three had lesions in more than one area including: mouth, gingiva, soft palate, lip, buccal mucosa and tongue, and one patient had lesions in the lip, tongue, oral mucosa, gingiva, soft palate and hard palate.

The most prevalent diagnosis was pemphigus vulgaris in both sexes $(45.4 \%$ 
among men and $65.9 \%$ among women). Low frequency of cigarette smoking, alcoholism and illicit drug use was observed among patients with VBDs. Regarding the use of illicit drugs, it was found that non-drug users had more often pemphigus vulgaris than other diseases, with statistically significant difference ( $p$ $=0.017)$. The frequency distribution of diseases and its correlation with demographic characteristics and harmful habits, see Table 1.

With respect to the location of oral manifestations relating to dermatologic diseases, it was found that there was statistical association between the type of dermatologic disease and oral manifestations $(p=0.001)$. There was association between oral manifestations and absence of linear IgA dermatosis $(p=0.011)$, as well as between oral manifestation and absence of bullous pemphigoid ( $\mathrm{p}=$ 0.0006). However, there was an association between oral manifestations and pemphigus vulgaris $(\mathrm{p}=0.001)$, and 41 cases of pemphigus vulgaris exhibited oral diseases.

The gingiva was the most frequently affected area (25\%) followed by buccal mucosa $(18.2 \%)$ and lips (17.6\%). There was no statistically significant correlation between location of the lesion and type of disease $(p=0.990)$. The frequency distribution and location of oral manifestations by diagnosis of dermatologic diseases, see Table 2.

Dental conditions assessed with respect to the type of dermatologic diseases showed statistically significant difference only for pemphigus vulgaris $(\mathrm{p}=0.05)$. Patients with pemphigus vulgaris had periodontal/gingival disease (Table 3 ).

With respect to presence of teeth, 63 (91.3\%) patients were dentulous and 28 (40.6\%) wore some type of dental prosthesis. Regarding the assessment of

Table 1. Frequency distribution of the diseases relating to demographic characteristics and harmful habits.

\begin{tabular}{|c|c|c|c|c|c|c|c|c|c|c|c|c|c|c|c|c|c|c|c|c|c|c|}
\hline \multirow[t]{2}{*}{ Variables } & \multirow[t]{2}{*}{ Category } & \multicolumn{3}{|c|}{$\begin{array}{l}\text { Linear IgA } \\
\text { dermatosis }\end{array}$} & \multicolumn{3}{|c|}{$\begin{array}{c}\text { Epidermolysis } \\
\text { bullosa acquisita }\end{array}$} & \multicolumn{3}{|c|}{$\begin{array}{l}\text { Paraneoplastic } \\
\text { pemphigus }\end{array}$} & \multicolumn{3}{|c|}{$\begin{array}{l}\text { Pemphigus } \\
\text { vulgaris }\end{array}$} & \multicolumn{3}{|c|}{$\begin{array}{c}\text { Bullous } \\
\text { pemphigoid }\end{array}$} & \multicolumn{3}{|c|}{$\begin{array}{c}\text { Mucous } \\
\text { membrane } \\
\text { pemphigoid }\end{array}$} & \multicolumn{3}{|c|}{ Total } \\
\hline & & $\mathrm{n}$ & $\%$ & $\mathrm{p}$ & $\mathrm{n}$ & $\%$ & $\mathrm{p}$ & $\mathrm{n}$ & $\%$ & $\mathrm{p}$ & $\mathrm{n}$ & $\%$ & $\mathrm{p}$ & $\mathrm{n}$ & $\%$ & $\mathrm{p}$ & $\mathrm{n}$ & $\%$ & $\mathrm{p}$ & $\mathrm{n}$ & $\%$ & $\mathrm{p}$ value $\mathrm{a}^{\mathrm{a}}$ \\
\hline \multirow[t]{2}{*}{ Sex } & Male & 2 & 50 & 0.59 & 4 & 40 & 0.71 & 1 & 50 & 1.0 & 10 & 24.4 & 0.12 & 5 & 50 & 0.27 & 0 & 0 & 0.56 & 22 & 31.9 & 0.45 \\
\hline & Female & 2 & 50 & & 6 & 60 & & 1 & 50 & & 31 & 75.6 & & 5 & 50 & & 2 & 100 & & 47 & 68.1 & \\
\hline $\begin{array}{l}\text { Average age } \\
\text { (years) }\end{array}$ & & 4 & 40 & & 10 & 46.2 & & 2 & 39 & & 41 & 43.1 & & 10 & 62 & & 2 & 51.5 & & 69 & 50.8 & \\
\hline \multirow{2}{*}{ Race } & Non-white & 0 & 0 & 1.0 & 1 & 10 & 1.0 & 1 & 50 & 0.27 & 6 & 14.6 & 1.0 & 2 & 22 & 0.62 & 0 & 0 & 1.0 & 10 & 14.5 & 0.60 \\
\hline & White & 4 & 100 & & 9 & 90 & & 1 & 50 & & 35 & 85.4 & & 7 & 77.8 & & 2 & 100 & & 59 & 85.5 & \\
\hline \multirow{2}{*}{$\begin{array}{l}\text { Cigarette } \\
\text { smoker }\end{array}$} & Yes & 1 & 25 & 0.39 & 1 & 10 & 1.0 & 0 & 0 & 1.0 & 6 & 14.6 & 1.0 & 0 & 0 & 0.35 & 1 & 50 & 0.22 & 8 & 11.6 & 0.43 \\
\hline & No & 3 & 75 & & 9 & 90 & & 2 & 100 & & 35 & 85.4 & & 10 & 100 & & 1 & 50 & & 61 & 88.4 & \\
\hline $\begin{array}{l}\text { Alcoholic } \\
\text { beverage }\end{array}$ & Yes & 0 & 0 & 1.0 & 2 & 20 & 0.15 & 0 & 0 & 1.0 & 3 & 7.3 & 1.0 & 0 & 0 & 0.59 & 0 & 0 & 1.0 & 5 & 7.2 & 0.57 \\
\hline consumption & No & 4 & 100 & & 8 & 80 & & 2 & 100 & & 38 & 92.7 & & 10 & 100 & & 2 & 100 & & 64 & 92.8 & \\
\hline \multirow{2}{*}{$\begin{array}{l}\text { Illicit-drug } \\
\text { user }\end{array}$} & Yes & 0 & 0 & 1.0 & 1 & 10 & 0.27 & 0 & 0 & 1.0 & 0 & 0 & 0.16 & 0 & 0 & 1.0 & 1 & 50 & $0.06^{*}$ & 2 & 2.9 & $0.02^{*}$ \\
\hline & No & 4 & 100 & & 9 & 90 & 0.71 & 2 & 100 & & 41 & 100 & & 10 & 100 & & 1 & 50 & & 67 & 97.1 & \\
\hline
\end{tabular}

${ }^{a}$ Chi-square. ${ }^{*} \mathrm{p}<0.05$. 
Table 2. Frequency distribution and localization of oral manifestations by dermatologic disease.

\begin{tabular}{|c|c|c|c|c|c|c|c|c|c|c|c|c|c|c|c|c|c|c|c|c|c|c|}
\hline Variables & Category & \multicolumn{3}{|c|}{$\begin{array}{l}\text { Linear IgA } \\
\text { dermatosis }\end{array}$} & \multicolumn{3}{|c|}{$\begin{array}{c}\text { Epidermolysis } \\
\text { bullosa } \\
\text { acquisita }\end{array}$} & \multicolumn{3}{|c|}{$\begin{array}{c}\text { Paraneoplastic } \\
\text { pemphigus }\end{array}$} & \multicolumn{3}{|c|}{$\begin{array}{c}\text { Pemphigus } \\
\text { vulgaris }\end{array}$} & \multicolumn{3}{|c|}{$\begin{array}{c}\text { Bullous } \\
\text { pemphigoid }\end{array}$} & \multicolumn{3}{|c|}{$\begin{array}{l}\text { Mucous } \\
\text { membrane } \\
\text { pemphigoid }\end{array}$} & \multicolumn{3}{|c|}{ Total } \\
\hline \multirow{2}{*}{$\begin{array}{c}\text { Oral } \\
\text { manifestations } \\
\text { at time of } \\
\text { examination }\end{array}$} & Yes & 1 & 25 & $0.01^{\star}$ & 8 & 80 & 0.65 & 2 & 100 & 1.0 & 41 & 100 & $0.001^{\star}$ & 4 & 40 & $0.0006^{\star}$ & 2 & 100 & 1.0 & 58 & 84.1 & \multirow{2}{*}{$0.001^{\star}$} \\
\hline & No & 3 & 75 & & 2 & 20 & & 0 & 0 & & 0 & 0 & & 6 & 60 & & 0 & 0 & & 11 & 15.9 & \\
\hline \multirow{6}{*}{$\begin{array}{l}\text { Localization } \\
\text { of } \\
\text { manifestation }\end{array}$} & Gingiva & 0 & 0 & 0.56 & 6 & 24 & 0.97 & 2 & 18.2 & 0.96 & 33 & 25.6 & 0.082 & 1 & 20 & 0.067 & 2 & 40 & 0.087 & 44 & 25 & \multirow[t]{6}{*}{0.990} \\
\hline & $\begin{array}{l}\text { Buccal } \\
\text { mucosa }\end{array}$ & 0 & 0 & & 4 & 16 & & 2 & 18.2 & & 24 & 18.6 & & 1 & 20 & & 1 & 20 & & 32 & 18.2 & \\
\hline & Lips & 1 & 100 & & 6 & 24 & & 2 & 18.2 & & 21 & 16.3 & & 0 & 0 & & 1 & 20 & & 31 & 17.6 & \\
\hline & Tongue & 0 & 0 & & 3 & 12 & & 2 & 18.2 & & 20 & 15.5 & & 2 & 40 & & 0 & 0 & & 27 & 15.3 & \\
\hline & Soft palate & 0 & 0 & & 2 & 8 & & 1 & 9.1 & & 14 & 10.9 & & 0 & 0 & & 0 & 0 & & 17 & 9.7 & \\
\hline & Hard palate & 0 & 0 & & 1 & 4 & & 0 & 0 & & 6 & 4.7 & & 0 & 0 & & 0 & 0 & & 7 & 4 & \\
\hline
\end{tabular}

${ }^{\mathrm{a} C h i}$-square. ${ }^{*} \mathrm{p}<0.05$.

Table 3. Frequency distribution of patients with gingival inflammation. Dental conditions by dermatological disease.

\begin{tabular}{|c|c|c|c|c|c|c|c|c|c|c|c|c|c|c|c|c|c|c|c|c|c|c|}
\hline Variables & Category & \multicolumn{3}{|c|}{$\begin{array}{l}\text { Linear IgA } \\
\text { dermatosis }\end{array}$} & \multicolumn{3}{|c|}{$\begin{array}{c}\text { Epidermolysis } \\
\text { bullosa acquisita }\end{array}$} & \multicolumn{3}{|c|}{$\begin{array}{l}\text { Paraneoplastic } \\
\text { pemphigus }\end{array}$} & \multicolumn{3}{|c|}{$\begin{array}{l}\text { Pemphigus } \\
\text { vulgaris }\end{array}$} & \multicolumn{3}{|c|}{$\begin{array}{c}\text { Bullous } \\
\text { pemphigoid }\end{array}$} & \multicolumn{3}{|c|}{$\begin{array}{l}\text { Mucous } \\
\text { membrane } \\
\text { pemphigoid }\end{array}$} & \multicolumn{3}{|c|}{ Total } \\
\hline \multirow{4}{*}{$\begin{array}{c}\text { Gingival } \\
\text { inflammation } \\
\text { in dentulous } \\
\text { patients } \\
(n=63)\end{array}$} & Yes & 3 & 100 & 0.98 & 8 & 80 & 1.0 & 2 & 100 & 0.37 & 38 & 97.4 & $0.05^{\star}$ & 8 & 100 & 0.19 & 0 & 0 & 0.37 & 59 & 93.6 & 0.42 \\
\hline & No & 0 & 0 & & 2 & 20 & & 0 & 0 & & 1 & 2.6 & & 0 & 0 & & 1 & 100 & & 4 & 6.4 & \\
\hline & Dentado total & 3 & 75.0 & & 6 & 60.0 & & 2 & 50.0 & & 20 & 48.8 & & 3 & 30.0 & & 1 & 50.0 & & 35 & 50.7 & 0.42 \\
\hline & $\begin{array}{c}\text { Total } \\
\text { dentulous }\end{array}$ & 3 & 75 & 0.20 & 6 & 60 & 0.48 & 2 & 50 & 0.13 & 20 & 48.8 & 0.28 & 3 & 30 & 0.24 & 1 & 50 & 0.13 & 35 & 50.7 & 0.42 \\
\hline \multirow{2}{*}{$\begin{array}{l}\text { Presence } \\
\text { of teeth }\end{array}$} & $\begin{array}{c}\text { Total } \\
\text { edentulous }\end{array}$ & 1 & 25 & & 0 & 0 & & 0 & 50 & & 2 & 4.9 & & 2 & 20 & & 1 & 50 & & 6 & 8.7 & \\
\hline & $\begin{array}{c}\text { Partially } \\
\text { edentulous- } \\
\text { minimal } \\
\text { absence } \\
1 \text { tooth }\end{array}$ & 0 & 0 & & 4 & 40 & & 0 & 0 & & 19 & 46.3 & & 5 & 50 & & 0 & 0 & & 28 & 40.6 & \\
\hline \multirow{2}{*}{$\begin{array}{l}\text { Prosthesis } \\
\text { wearing }\end{array}$} & Yes & 1 & 25 & 0.64 & 2 & 20 & 0.18 & 0 & 0 & 0.51 & 17 & 41.5 & 1.0 & 7 & 70 & 1.0 & 1 & 50 & 1.0 & 28 & 40.6 & 0.07 \\
\hline & No & 3 & 75 & & 8 & 80 & & 2 & 100 & & 24 & 58.5 & & 3 & 30 & & 1 & 50 & & 41 & 59.4 & \\
\hline $\begin{array}{l}\text { Complete } \\
\text { dental }\end{array}$ & Yes & 1 & 25 & 0.98 & 1 & 10 & 0.68 & 0 & 0 & 1.0 & 6 & 14.6 & 0.53 & 3 & 30 & 0.36 & 1 & 50 & 0.32 & 12 & 17.4 & 0.58 \\
\hline prosthesis & No & 3 & 75 & & 9 & 90 & & 2 & 100 & & 35 & 85.4 & & 7 & 70 & & 1 & 50 & & 57 & 82.6 & \\
\hline $\begin{array}{c}\text { Removable } \\
\text { partial }\end{array}$ & Yes & 0 & 0 & 0.57 & 2 & 20 & 0.72 & 0 & 0 & 1.0 & 12 & 29.3 & 0.58 & 4 & 40 & 0.43 & 0 & 0 & 1.0 & 18 & 26.1 & 0.52 \\
\hline \multirow{2}{*}{$\begin{array}{c}\text { Fixed } \\
\text { prosthesis }\end{array}$} & Yes & 0 & 0 & 1.0 & 0 & 0 & 0.58 & 0 & 0 & 1.0 & 5 & 12.2 & 0.69 & 2 & 20 & 0.27 & 0 & 0 & 1.0 & 7 & 10.1 & 0.66 \\
\hline & No & 4 & 100 & & 10 & 100 & & 2 & 100 & & 36 & 87.8 & & 8 & 80 & & 2 & 100 & & 62 & 89.9 & \\
\hline
\end{tabular}

${ }^{\mathrm{a}}$ Chi-square. ${ }^{\star} \mathrm{p}<0.05$. 
gingival inflammation, 59 (93.6\%) patients exhibited some index of gingival inflammation of dental origin. Gingival inflammation was present in $100 \%$ of patients with bullous pemphigoid, linear IgA dermatosis, paraneoplastic pemphigus, and in $97.4 \%$ of patients with pemphigus vulgaris, with no statistically significant correlation between inflammation and disease $(\mathrm{p}=0.42)$.

Regarding drug treatment, 27 (46.5\%) of 58 patients with oral manifestations received more than one drug simultaneously: prednisone associated with topical corticosteroids (37.0\%), prednisone associated with azathioprine (14.8\%), prednisone associated with mycophenolate mofetil (11.1\%), prednisone associated with dapsone (7.4\%), prednisone associated with topical corticosteroids and azathioprine (7.4\%), prednisone associated with topical corticosteroids and dapsone (3.7\%), prednisone associated topical corticosteroids and mycophenolate mofetil (3.7\%), prednisone associated with aciclovir (3.7\%), and prednisone associated with topical corticosteroid and azathioprine and cyclophosphamide (3.7\%), topical corticosteroid associated with dapsone (3.7\%), topical corticosteroid associated with azathioprine (3.7\%).

The rest of the patients $(\mathrm{n}=31)$ were treated with only one drug, namely, prednisone (64.5\%), mycophenolate mofetil (3.2\%), dapsone (3.2\%), topical corticoid (3.2\%). Seven (22.58\%) patients maintained the disease under control without drug therapy.

A systemic disease associated with VBDs was observed in $52.2 \%$ of the patients. Among them, 52.3\% had skeletal muscle disease (mainly osteoporosis), 44.9\% had digestive disease, $34.8 \%$ had cardiovascular disease, and $18.8 \%$ had metabolic disease. For these patients, drug therapy required the combination of one or more medications to treat or control the systemic disease. Furthermore, $24.7 \%$ patients used gastric protectors, $22.7 \%$, vitamin D, $22.4 \%$, calcium supplement, $16.5 \%$, antihypertensive drugs, $6.8 \%$, statin, $6.0 \%$, hypoglycemic drugs, and $1.5 \%$ did thyroid hormone replacement.

With respect to systemic diseases, it was found that there was statistically significant association between metabolic diseases and dermatologic diseases, especially pemphigus vulgaris $(\mathrm{p}=0.011)$. There was statistically significant association between metabolic diseases and bullous pemphigoid $(p=0.002)$, and between respiratory diseases and bullous pemphigoid $(p=0.03)$.

\section{Discussion}

Despite small sample for evaluation of oral manifestations and their relation with VBD, assessment of oral manifestations in Dermatology Outpatient Clinic was an innovative study and, therefore, the results of the present study can significantly contribute to the clinical practice.

The average age between the fourth and sixth decade of life has been found in other studies; however, this finding does not exclude the possibility of this pathology be present among children and adolescents [10] [11]. The predominance of women can be explained by the characteristic of their specific autoimmune system and the fluctuation of sex hormones that takes place during the men- 
strual cycle, pregnancy and menopause, what has a correlation with the incidence of systemic autoimmune diseases in women. These diseases can be explained by epigenetic theories related to $\mathrm{X}$ chromosome and the amount of immune-related genes which suggest women's specific mechanisms of autoimmunity [12] [13].

The predominance of white patients in study is in line with the data found in the literature. One of the explanations for this incidence is the presence of the HLA gene that confers immunological protection against desmoglein-1, an auto-antibody that also determines the development of VBDs [14].

Due to the specificity and chronicity of VBDs, treatments are usually conducted by dermatologists in reference centers. However, initial manifestations can occur in oral cavity and dental surgeons should be prepared to recognize them and prescribe appropriate treatments. This reinforces the need for interdisciplinary health care teams to treat patients [15] [16].

The drug treatment applied to patients is in agreement with the literature. The use of dapsone is considered the first-line treatment in some patients with IgA monotherapy or in combination with systemic corticosteroids. In patients with pemphigus vulgaris, this treatment may be effective as monotherapy or associated with immunosuppressant's. In patients with bullous pemphigoid or mucous membrane pemphigoid, dapsone has been effective in association with immunosuppressive therapy [17]. The use of cyclophosphamide in pulse therapy associated with prednisone for pemphigus results in a prednisone sparing-effect, as seen in a case of this study [18]. Mycophenolate mofetil in combination with corticosteroids is described as effective in the rapid and complete remission of pemphigus vulgaris [19]. The use of prednisone alone in the treatment of pemphigus demonstrated a total reduction of oral manifestations in a case study [20].

\subsection{Dermatological Disease and Oral Manifestation}

Regarding oral manifestations of VBDs, paraneoplastic pemphigus, pemphigus vulgaris, bullous pemphigoid, mucous membrane pemphigoid and acquired bullous epidermolysis bullosa presented oral lesions. Other studies show the relationship between the dermatological disease and oral manifestations in patients with pemphigus vulgaris, bullous pemphigoid and erythema multiform [21] [22].

Frequent oral manifestations of VBDs were present in paraneoplastic pemphigus, pemphigus vulgaris and mucous membrane pemphigoid, a fact directly related to the characteristics of the disease. In the case of paraneoplastic pemphigus, lesions involving the mucosa are common and often characterized as stomatitis. These lesions affect the oral mucosa and lips and do not respond to conventional treatment established for autoimmune bullous diseases [23].

Regarding the location of oral lesions, in this study a greater involvement of oral structures (floor, buccal mucosa, gingiva and soft palate) was observed than 
an epidemiological study in Taiwan, with 11 patients that had paraneoplastic pemphigus presenting lip and tongue erosive recalcitrant lesions [24].

Pemphigus vulgaris was the most frequent diagnosis found in the present study, similar to what is found in other studies [1] [4] [25]. Literature reports the predominance of this diagnosis in female patients [1], which can explain the high incidence found in the present study, with predominance of female patients.

Oral manifestations of pemphigus vulgaris start with fluid-filled blisters that can be localized or diffuse with a tendency to expand. In general, the blisters have thin walls and they break easily and cause painful lesions with multiple ulcerations [26].

Regarding the incidence and location of lesions, the results of this study are similar to an investigation carried out in a dermatology center that found oral lesions in $23 \%(\mathrm{n}=8)$ of the patients with pemphigus vulgaris in the oral mucosa, lateral border of the tongue and palate [27]. In the present study, lesions in the gums, lips and floor of the mouth were observed.

The low frequency of harmful habits, such as cigarette smoking, alcohol consumption, and use of illicit drugs in group studied can be explained by discomfort that these substances generate. In addition, patients become aware about the systemic and local damaging effects of using these substances in combination with therapies [10].

The significant correlation between pemphigus vulgaris and non-users of illicit drugs in study $(\mathrm{p}=0.017)$ has not been found in other studies. However, other studies have shown the relationship between the use of cocaine and ulcerative lesions in the skin and mucosa, and aggravation of systemic diseases, which require in-depth knowledge of health care professionals for recognition and early intervention [28] [29].

Even though mucous membrane pemphigoid can affect any mucous membrane, this is clinically more common in the oral mucosa and can be the first and only manifestation of the disease [11].

In patients with mucous membrane pemphigoid, the lesions can affect the periodontal health, especially by causing the development of supra gingival dental plaque. Furthermore, it worsens periodontal parameters, including periodontal pocket depth, probing attachment level, degree of dental mobility and bleeding [11].

In a control case study, patients with mucous membrane pemphigus and oral involvement concluded that patients diagnosed with mucous membrane pemphigus have higher levels of gingival and periodontal inflammation than control patients who were healthy [30].

Although only one patient was diagnosed with mucous membrane pemphigus, the oral involvement that expanded to the lip, buccal mucosa, gingiva and soft palate showed a manifestation of gingival/periodontal disease as described in the literature. 
In bullous pemphigoid, autoantibodies were present at the dermo-epidermal junction and they attack the hemi desmosomes, causing complete separation of the epidermis from the dermis. This was characterized by itchy, itchy bubbles that break after several days leaving scabs. Most patients did not suffer from oral involvement. Occasionally, the disease may manifest a non-bullous eruption consisting of polymorphic and non-specific lesions, such as erythematous papules and plaques and urticarious [31].

Oral lesions in patients with bullous pemphigoid were found in a study that investigated the characteristics of such oral lesions. The six patients included in the sample had lesions on the palate, epiglottis, gingiva, hypopharynx, tongue, nasal cavity and buccal mucosa. These lesions consisted of erosions, erosions with white coating, erythematous spots and/or blisters [32].

Acquired bullous epidermolysis (ABE) is a chronic bullous disease of the skin and mucous membranes characterized by sub epidermal blisters. The oral mucosa presents multiple blisters and erosions and is most commonly described in patients with non-inflammatory forms [11].

A study with 12 patients with $\mathrm{ABE}$ reported oral mucosa involvement in 9 patients, what corresponds to $75 \%$ of the patients [33]. In turn, we found oral involvement in $83.3 \%$ of the sample, and among these, one patient had numerous oral lesions.

\subsection{Periodontal Disease as an Inflammatory Factor}

The oral manifestation characterized by significant amount of lesions observed in the absence of linear IgA dermatosis $(\mathrm{p}=0.011)$ and bullous pemphigoid $(\mathrm{p}=$ 0.0006) indicates occurrence of lesions prior to manifestation of VBDs. Regarding pemphigus vulgaris, a significant periodontal disease was observed $(\mathrm{p}=$ 0.05). This disease could lead to drug treatment for dermatologic disease without positive results because another type of treatment was required.

Location of the lesion and the type of disease were not significantly correlated. However, as reported in literature, the gingiva was the most commonly affected region [1] [34]. Manifestations in gingiva usually occur as desquamative gingivitis. The high frequency of this manifestation observed in study stresses the importance of differential diagnosis for infectious and inflammatory disorders of dental origin associated with dental plaque or calculus [6].

With respect to linear IgA dermatosis, mucous membrane involvement was observed in $80 \%$ of the patients. They were painful ulcerative lesions that follow the rupture of blisters, which sometimes appear in the form of erosive or desquamative gingivitis [11]. In patients with bullous pemphigoid, oral involvement was observed in $10 \%$ to $30 \%$ of cases, occurring in the form of erosion and more rarely as blisters. This was the only autoimmune disease in which the incidence increases with age [26].

Persistent oral lesions of pemphigus vulgaris prevent effective brushing, leading to an increase in the dental biofilm and consequently worsening of the dermatological disease [17]. A study evaluating periodontal disease in 50 patients 
with pemphigus vulgaris concluded that patients with pemphigus vulgaris may be involved in initiation or progression of periodontitis and that this association increases with severity of dermatological disease [35].

These oral manifestations cause local discomfort directly affecting physical and psychic aspects and quality of life of the patients [36]. There were few studies in the literature correlating VBDs of the oral cavity with gingival inflammation or periodontal diseases that can be important factors in the evolution in these patients.

A study on periodontal disease and its influence on systemic disease discusses the possibility of periodontal disease have an aggravating influence on chronic and systemic diseases due to infectious and inflammatory factors. The study reinforces that there is evidence that periodontal treatment leads to decreased blood concentrations of periodontal bacteria and inflammatory markers. Therefore, the incidence and severity of such systemic diseases can be intuitively expected to improve by periodontal treatment [37].

The presence of gingival inflammation in all patients with bullous pemphigoid, linear IgA dermatosis and mucous membrane pemphigoid, as well as in most of the patients affected by pemphigus vulgaris, corroborates the findings in literature. The presence of gingival inflammatory diseases can be one of the main factors responsible for the maintenance of vesiculobullous lesions, especially in cases when cutaneous lesions have satisfactory therapeutic responses [38].

Persistent oral lesions, lack of effective oral hygiene and plaque buildup may increase the risk of long-term periodontal disease. However, little is discussed about the relationship between the presence of gingival pemphigus and periodontal health. A study that evaluates the possible impact of gingival pemphigoid lesions in the periodontium concluded that patients with mucous membrane pemphigoid currently under treatment have higher plaque indexes than patients in remission and not undergoing treatment at the time [39].

In the case of dental management, oral hygiene instruction and patient motivation should be done to avoid biofilm-induced gingivitis, which may aggravate or worsen the disease. Proper and meticulous oral hygiene with the use of a toothbrush of the bristles can relieve some of the discomfort of the patient. An antiplaque agent, such as gluconate of chlorhexidine $0.12 \%$ taken twice daily, may have beneficial effects in situations that represent a discomfort for hygiene [40].

The recommendation for prevention of local irritation with food restriction for spicy foods as well as rigid foods and follow-up with dentist surgeon for periodontal treatment may contribute to the control of periodontal disease in patients with dermatological disease [11].

A high proportion of patients who wore some type of dental prosthesis were observed in the group assessed. This condition may cause discomfort and difficulty in the performance of oral hygiene, ultimately contributing to unsatisfactory evolution and maintenance of oral lesions. Therefore, further studies should 
be conducted to assess the association between dental prostheses and quality of life.

Among the limitations of this study, is a single evaluation center, a small number of patients evaluated. The subjects were 69 patients, but there were very few cases of linear IgA dermatosis, paraneoplastic pemphigus, and mucous membrane pemphigoid, and they are inadequate to clarify the characteristics within the oral cavity and for statistical analysis.

\section{Conclusion}

The high frequency of patients with inflammatory gingival diseases stresses the importance of specific dental management. Although the association between gingival inflammation and VBDs has not yet been proven, there is some clinical evidence indicating that gingival health care generates better results in the control of VBDs with oral manifestations. This fact may be a promising line of research.

\section{Conflict in Interest}

No conflict.

\section{Financial Support}

No financial.

\section{References}

[1] Vassileva, S., Drenovska, K. and Manuelyan, K. (2014) Autoimmune Blistering Dermatoses as Systemic Diseases. Clinics in Dermatology, 32, 364-375. https://doi.org/10.1016/j.clindermatol.2013.11.003

[2] Brick, K.E., Weaver, C.H., Lohse, C.M., Pittelkow, M.R., Lehman, J.S., Camilleri, M.J., et al. (2014) Incidence of Bullous Pemphigoid and Mortality of Patients with Bullous Pemphigoid in Olmsted County, Minnesota, 1960 through 2009. Journal of the American Academy of Dermatology, 71, 92-99. https://doi.org/10.1016/j.jaad.2014.02.030

[3] Said, S. and Golitz, L. (2011) Vesiculobullous Eruptions of the Oral Cavity. Otolaryngologic Clinics of North America, 44, 133-160. https://doi.org/10.1016/j.otc.2010.09.005

[4] Mays, J.W., Sarmadi, M. and Moutsopoulos, N.M. (2012) Oral Manifestations of Systemic Autoimmune and Inflammatory Diseases: Diagnosis and Clinical Management. Journal of Evidence-Based Dental Practice, 12, 265-282. https://doi.org/10.1016/S1532-3382(12)70051-9

[5] Munhoz Ede, A., Cardoso, C.L., Barreto, J.A., Soareas, C.T. and Damante, J.H. (2011) Severe Manifestation of Oral Pemphigus. American Journal of Otolaryngology, 32, 338-342. https://doi.org/10.1016/j.amjoto.2010.03.005

[6] Martin, M.D. (2009) Gingival Nikolsky's Sign Is Useful for Clinical Diagnosis. Journal of Evidence-Based Dental Practice, 9, 217-218. https://doi.org/10.1016/j.jebdp.2009.06.004

[7] Ramos-e-Silva, M., Ferreira, A. and Jacques, C. (2011) Oral Involvement in Au- 
toimmune Bullous Diseases. Clinics in Dermatology, 29, 443-454.

https://doi.org/10.1016/j.clindermatol.2011.01.015

[8] Sebaratnam, D.F. and Murrell, D.F. (2011) Objective Scoring Systems for Disease Activity in Autoimmune Bullous Disease. Dermatologic Clinics, 29, 515-520.

https://doi.org/10.1016/j.det.2011.03.015

[9] Lobene, R.R., Weatherford, T., Ross, N.M., Lamm, R.A. and Menaker, L. (1986) A Modified Gingival Index for Use in Clinical Trials. Clinical Preventive Dentistry, 8, 3-6.

[10] Ruocco, V., Ruocco, E., Lo Schiavo, A., Brunetti, G., Guerrera, L.P. and Wolf, R. (2013) Pemphigus: Etiology, Pathogenesis, and Inducing or Triggering Factors: Facts and Controversies. Clinics in Dermatology, 31, 374-381. https://doi.org/10.1016/j.clindermatol.2013.01.004

[11] Sticherling, M. and Erfurt-Berge, C. (2012) Autoimmune Blistering Diseases of the Skin. Autoimmunity Reviews, 11, 226-230. https://doi.org/10.1016/j.autrev.2011.05.017

[12] Markle, J.G. and Fish, E.N. (2014) SeXX Matters in Immunity. Trends in Immunology, 35, 97-104. https://doi.org/10.1016/j.it.2013.10.006

[13] Zhao, C.Y. and Murrell, D.F. (2015) Autoimmune Blistering Diseases in Females: A Review. International Journal of Women's Dermatology, 1, 4-12. https://doi.org/10.1016/j.ijwd.2015.01.002

[14] Gupta, V.K., Kelbel, T.E., Nguyen, D., Melonakos, K.C., Murrell, D.F., Xie, Y., et al. (2011) A Globally Available Internet-Based Patient Survey of Pemphigus Vulgaris: Epidemiology and Disease Characteristics. Dermatologic Clinics, 29, 393-404. https://doi.org/10.1016/j.det.2011.03.016

[15] Carvalho Junior, J.R. (2012) Interrelationship between Oral and Systemic Diseases: The Role of the Dental Surgeon in Diagnosis and Treatment. Oral Science, 4, 2-5. https://portalrevistas.ucb.br/index.php/oralsciences/article/view/8400

[16] Gonçalves, P.G.P., Serpa, M.S., Pereira, L.L., Silveira, E.J.D.S., Glavão, H.C., Freitas, R.A., et al. (2015) Periodontal Manifestations Associated with Autoimmune Diseases: A Literature Review. Revista Brasileira de Medicina, 72, 423-429. http://www.moreirajr.com.br/revistas.asp?fase=r003\&id_materia=6213

[17] Navarro Triviño, F.J., Ruíz Villaverde, R., Díaz Martínez, M.A. and Naranjo Sintes, R. (2017) Dapsone: Update of a Classic Drug in Current Dermatological Uses. Piel, 32, 173-177.

[18] Fernandes, N.C. and Menezes, M. (2013) Pulse Therapy in Pemphigus: Report of 11 Cases. Anais Brasileiros de Dermatologia, 88, 672-675. https://doi.org/10.1590/abd1806-4841.20131840

[19] Strowd, L.C., Taylor, S.L., Jorizzo, J.L. and Namazi, M.R. (2011) Therapeutic Ladder for Pemphigus Vulgaris: Emphasis on Achieving Complete Remission. Journal of the American Academy of Dermatology, 64, 490-494. https://doi.org/10.1016/j.jaad.2010.02.052

[20] Ferreira, V.Y.N., Lyra, T.C., Pereira, L.L., Nascimento, M.A.B., Souza, L.B. and Bonan, P.R.F. (2016) Therapeutic Effectiveness of Systemic Steroid on Oral Pemphigus Vulgaris Treatment. Arquivos de Ciências da Saúde, 23, 10-13. https://doi.org/10.17696/2318-3691.23.3.2016.215

[21] Carvalho, C.H., Santos, B.R., Vieira Cde, C., Lima, E.d., Santos, P.P. and Freitas Rde, A. (2011) An Epidemiological Study of Immune-Mediated Skin Diseases Affecting the Oral Cavity. Anais Brasileiros de Dermatologia, 86, 905-909. https://doi.org/10.1590/S0365-05962011000500007 
[22] Jaafari-Ashkavandi, Z., Mardani, M., Pardis, S. and Amanpour, S. (2011) Oral Mucocutaneous Diseases: Clinicopathologic Analysis and Malignant Transformation. Journal of Craniofacial Surgery, 22, 949-951. https://doi.org/10.1097/SCS.0b013e31820fe1f0

[23] Moreira, A.A.M.S.S., Rodrigues, O.C.S.F. and Mota, A.J.V. (2013) Autoimmune Blistering Diseases. Revista da Sociedade Portuguesa de Dermatologia e Venereologia, 71, 325-335.

[24] Cho, Y.-T., Kao, J.-T., Chen, H.-J., Wang, L.-F. and Chu, C.-Y. (2014) Paraneoplastic Pemphigus: A Retrospective Case Series in a Referral Center in Northern Taiwan. Dermatologica Sinica, 32, 1-6. https://doi.org/10.1016/j.dsi.2013.04.006

[25] Baum, S., Sakka, N., Artsi, O., Trau, H. and Barzilai, A. (2014) Diagnosis and Classification of Autoimmune Blistering Diseases. Autoimmunity Reviews, 13, 482-489. https://doi.org/10.1016/j.autrev.2014.01.047

[26] Mustafa, M.B., Porter, S.R., Smoller, B.R. and Sitaru, C. (2015) Oral Mucosal Manifestations of Autoimmune Skin Diseases. Autoimmunity Reviews, 14, 930-951. https://doi.org/10.1016/j.autrev.2015.06.005

[27] Kaur, B. and Sheikh, S. (2013) Clinical Evaluation of Oral Lesions Associated with Dermatologic Diseases. Archives of Oral Research, 9, 15-22. https://doi.org/10.7213/archivesoforalresearch.09.001.AO01

[28] Hennings, C. and Miller, J. (2013) Illicit Drugs: What Dermatologists Need to Know. Journal of the American Academy of Dermatology, 69, 135-142. https://doi.org/10.1016/j.jaad.2012.12.968

[29] Brewer, J.D., Meves, A., Bostwick, J.M., Hamacher, K.L. and Pittelkow, M.R. (2008) Cocaine Abuse: Dermatologic Manifestations and Therapeutic Approaches. Journal of the American Academy of Dermatology, 59, 483-487. https://doi.org/10.1016/j.jaad.2008.03.040

[30] Arduino, P.G., Farci, V., D’Aiuto, F., Carcieri, P., Carbone, M. and Tanteri, C. (2011) Periodontal Status in Oral Mucous Membrane Pemphigoid: Initial Results of a Case-Control Study. Oral Diseases, 17, 90-94. https://doi.org/10.1111/j.1601-0825.2010.01709.x

[31] Kershenovich, R., Hodak, E. and Mimouni, D. (2014) Diagnosis and Classification of Pemphigus and Bullous Pemphigoid. Autoimmunity Reviews, 13, 477-481. https://doi.org/10.1016/j.autrev.2014.01.011

[32] Ohki, M., Kikuchi, S., Ohata, A., Baba, Y., Ishikawa, J. and Sugimoto, H. (2016) Features of Oral, Pharyngeal, and Laryngeal Lesions in Bullous Pemphigoid. Ear, Nose \& Throat Journal, 95, E1-E5.

[33] Iranzo, P., Herrero-González, J.E., Mascaró-Galy, J.M., Suárez-Fernández, R. and España, A. (2014) Epidermolysis Bullosa Acquisita: A Retrospective Analysis of 12 Patients Evaluated in Four Tertiary Hospitals in Spain. British Journal of Dermatology, 171, 1022-1030. https://doi.org/10.1111/bjd.13144

[34] Rebouças, D.S., Cerqueira, L.S., Costa, T.F., Ferreira, T.G., Naves, R.C. and Zerbinati, L.P.S. (2014) Pemphigus Vulgaris the Importance of Knowledge of the Surgeon Dentist for a Correct Diagnosis. Revista Bahiana de Odontologia, 5, 174-181.

[35] Thorat, M.S., Raju, A. and Pradeep, A.R. (2010) Pemphigus Vulgaris: Effects on Periodontal Health. Journal of Oral Science, 52, 449-454.

https://doi.org/10.2334/josnusd.52.449

[36] Sebaratnam, D.F., Frew, J.W., Davatchi, F., et al. (2012) Quality-of-Life Measure- 
ment in Blistering Diseases. Dermatologic Clinics, 30, 301-307.

https://doi.org/10.1016/j.det.2011.11.008

[37] Borgnakke, W.S. (2015) Does Treatment of Periodontal Disease Influence Systemic Disease? Dental Clinics of North America, 59, 885-917.

https://doi.org/10.1016/j.cden.2015.06.007

[38] Lo Schiavo, A., Ruocco, E., Brancaccio, G., Caccavale, S., Ruocco, V. and Wolf, R. (2013) Bullous Pemphigoid: Etiology, Pathogenesis, and Inducing Factors: Facts and Controversies. Clinics in Dermatology, 31, 391-399.

https://doi.org/10.1016/j.clindermatol.2013.01.006

[39] Tricamo, M.B., Rees, T.D., Hallmon, W.W., Wright, J.M., Cueva, M.A. and Plemons, J.M. (2006) Periodontal Status in Patients with Gingival Mucous Membrane Pemphigoid. Journal of Periodontology, 77, 398-405.

https://doi.org/10.1902/jop.2006.050113

[40] Gagari, E. and Damoulis, P.D. (2011) Desquamative Gingivitis as a Manifestation of Chronic Mucocutaneous Disease. Journal der Deutschen Dermatologischen Gesellschaft, 9, 184-187. https://doi.org/10.1111/j.1610-0387.2010.07543.x 